\author{
ЛИНГВИСТИЧЕСКАЯ РЕПРЕЗЕНТАЦИЯ ХУДОЖЕСТВЕННОГО \\ КОНЦЕПТА ОНА-ЖЕНЩИНА \\ (НА МАТЕРИАЛЕ АВТОБИОГРАФИЧЕСКОГО РОМАНА \\ МАРИИ АРБАТОВОЙ МНЕ 46) \\ A LINGUISTIC REPRESENTATION OF THE ARTISTIC CONCEPT \\ OF "SHE-WOMAN" \\ (BASED ON THE AUTOBIOGRAPHICAL NOVEL I AM 46 YEARS OLD \\ BY MARIA ARBATOVA)
}

\title{
ANASTASIA OSHCHEPKOVA
}

\begin{abstract}
This work is related to the field of linguo-cultural studies, and also touches on the area of cognitive linguistics. The purpose is to describe the concept of "SHE - WOMEN" by analyzing text vocabulary which relates to a reduced style and which is distributed into lexical-thematic groups.

The practical part of this article includes a description of each of the selected lexicalthematic groups. In the final part of the work, I describe the concept of "SHE - WOMEN" and draw conclusions.
\end{abstract}

Anastasia Oshchepkova, Uniwersytet im. Adama Mickiewicza w Poznaniu, Poznań - Polska, anastasia.oschepkova@gmial.com

В современном мире науки наблюдается устойчивая тенденция к взаимодействию различных научных областей. Лингвистика - наука, которая придерживается последних тенденций и постепенно включается в сотрудничество со многими смежными и более отдаленными научными направлениями. Взаимодействие научных сфер направлено на достижение, как правило, единой общей цели: углубленного познания человека, его деятельности и окружающей его действительности.

Результатом текущих тенденций является зарождение и интенсивное развитие новых направлений в сфере науки. К числу новых научных дисциплин можно отнести когнитивную лингвистику и лингвокультурологию. Настоящую статью можно причислить к области лингвокультурологии, которая относится к языку как к носителю определенной национальной ментальности 1 . Кроме того, работа затрагивает область когнитивной лингвистики. c. 22.

1 3.Д. П о п о в а, И.А. С т е р н и н, Когнитивная лингвистика, Москва 2010, 
Когнитивная лингвистика - это относительно молодое направление в языкознании. Его основной задачей является изучение проблем соотношения языка и человеческого сознания, роли языка в категоризации мира и обобщении человеческого опыта ${ }^{2}$. Когнитивная лингвистика оперирует рядом понятий. Ключевым из них является понятие концепт. Подробный анализ концептов, „культурно-ментально-языковых образований, сгустков культуры в сознании человека [...], тех пучков представлений, понятий, знаний, ассоциаций, которые сопровождают слово" 3 , представляет немалый интерес для современных лингвистов, так как открывает новые возможности в изучении языка и является одним из способов реконструкции человеческого сознания.

Данное исследование является лишь небольшим фрагментом работы по изучению сложного концепта ЖЕНЩИНА. На данном этапе нашей целью является изучение только одной из составляющих сложного концепта. В частности мы намереваемся описать подконцепт ОНА-ЖЕНЩИНА с помощью анализа языкового материала русского источника. В будущем мы намерены описать и сопоставить остальные подконцепты сложного концепта ЖЕНЩИНА, которыми являются Я-ЖЕНЩИНА и МЫ-ЖЕНЩИНЫ, что позволит нам провести комплексный сопоставительный анализ сложного концепта на материале русской и польской языковой действительности.

В настоящей статье мы занимаемся подробным рассмотрением подконцепта ОНА-ЖЕНЩИНА с помощью анализа языкового материала русского источника. В качестве материала мы выбрали лексические единицы, эксцерпированные из автобиографического романа русской писательницы Марии Арбатовой Мне 46.

Мы намерены работать с текстом художественного произведения, так как уверены, что подобный материал представляет собой достоверный источник знаний о сознании русского человека. Мы разделяем точку зрения 3.Д. Поповой и И.А. Стернина о том, что при изучении языка имеется возможность

проникнуть в концептосферу людей, выяснить, что было важно для того или иного народа в разные периоды его истории, а что оставалось вне поля его зрения, в то время как для другого народа это оказывалось существенным $^{4}$.

Исследуя интересующий нас концепт, особенно важно принять во внимание исторический отрезок времени, в котором исследуемый материал

2 Е.В. Д з ю б а, Кониепт „ум" в русской лингъокультуре, Екатеринбург 2011, с. 3.

3 Ю.С. С т е п а н о в, Константы: словарь русской культуры, Москва 2004, с. 42-67.

4 3.Д. П о п о в а, И.А. С т е р н и н, указ. соч., с. 29. 
был создан. События, описанные в автобиографическом романе М. Арбатовой Мне 46, происходят на стыке XX и XXI веков. Данный исторический период, являясь закатом советского общества и зарождением нового - постсоветского, представляет для исследователей, а для нас в частности, особенный интерес. Такие колоссальные изменения в жизни страны не могут не оставить следа в языке. Ведь в языке незамедлительно отражаются даже малейшие изменения, происходящие в обществе, отображаются тенденции; язык - своеобразное связующее звено между человеческим сознанием и реальностью. Ученые согласны, что язык - резервуар знаний, кладовая информации о мире, о реальности, культурный факт, а также наиболее полный источник знаний о данной культуре. 5 Таким образом, изучая язык личности / народа, принимая при этом во внимание особенности исторического фона эпохи, мы получаем возможность познать особенности мышления данной личности / группы и достигнуть наиболее добросовестных результатов.

Как известно, художественные тексты представляют собой один из важнейших компонентов формирования менталитета, литература способна значительно влиять на наше мироощущение, а „писатели и поэты своим творчеством вносят серьезный вклад в формирование общей концептосферы национального языка" 6 . Текст автобиографического романа, являясь формой фиксации знаний о мире, представляет особенную ценность для наших исследований. Особенностью автобиографического произведения является то, что автор такого произведения заключает с читателями „автобиографическое соглашение”, в котором он утверждает, что будет писать правду7. Именно поэтому выбранный текст особенно ценен для исследователей концептов, ведь он является источником более или менее достоверных фактов из жизни реально существующего персонажа. Кроме этого, факты, представленные в таком произведении, дополнительно обогащены авторской оценкой, другими словами, пропущены через авторский оценочный фильтр. Арбатова запечатляет не только факты и события своей жизни, но также дает оценку происходящему с точки зрения носителя русского языка и русской культуры, используя средства русского языка, обогащенные элементами языка советской эпохи. Таким образом, базируясь в своих исследованиях на автобиографическом романе, мы получим четкую картину того, какова женщина постсоветского пространства, каковы ее ценности.

${ }^{5}$ J. A n u s i e w i c z, Kulturowa teoria języka. Zarys problematyki, Wrocław 1994, c. 17. 6 Д.С. Л и х а ч е в, Концеептосфера русского языка, [в:] Е.В. Д з ю б а, указ. соч., с. 12.

7 Ю.Л. С а п о ж н и к о в а, Жанр автобиографии: понятие и особенности, „Ученые записки Забайкальского государственного университета. Сер.: Филология, история, востоковедение" 2012, № 2, с. 56. 
Известный ученый С.А. Аскольдов делил концепты на познавательные и художественные. По его словам, концепты познания - это концепты общности, художественные же концепты более индивидуальны. Художественный концепт, по его мнению, является сочетанием понятий, представлений, чувств, эмоций ${ }^{8}$. Изучаемый нами концепт можно отнести к числу художественных концептов 9 , так как материалом для наших исследований является текст художественного произведения. Данные концепты носят индивидуальный характер и отражают уникальную систему представлений автора текста о мире, но, несмотря на это, их авторы - писатели и поэты - активно участвуют в построении и формировании общей концептосферы национального языка ${ }^{10}$.

Художественные концепты немаловажны для формирования национального менталитета. Они общедоступны и способны серьезно влиять на сознание всего народа посредством художественной литературы, именно поэтому сфера изучения художественных концептов представляется нам одной из наиболее значимых и ценных, а область изучения таких конщептов занимает отдельное место в лингвокультурологии.

Итак, специфика выбранного нами материала предполагает достижение следующих целей: построение и анализ образа постсоветской женщины через призму исторического контекста: современницы, которая значительную часть своей жизни прожила в СССР, где прошло ее детство, где сформировались взгляды, предпочтения; выяснение, удалось ли ей принять новую постсоветскую действительность. Нас интересует то, как сформировавшиеся в СССР ценности видоизменились на постсоветском пространстве, и изменились ли вообще.

В ходе анализа материала, эксцерпированного из произведения Арбатовой, нам удалось разделить интересующую нас лексику на несколько категорий. Выделенные элементы представляют собой цитаты из текста, мини-предложения, словосочетания, отдельно стоящие лексические единицы, относящиеся к различным частям речи. Ниже приведем названия выделенных категорий с выбранными примерами и кратким анализом, тем самым предпримем попытку воссоздания портрета конщепта ОНА-ЖЕНЩИНА.

8 С.А. А с к о л ь д о в, Концепт и слово, см.: Е.В. Д з ю б а, указ. соч., с. 34

9 Г.Д. Г а ч е в, Жизнь художественного сознания, Москва 1972; В.Г. 3 у с м а н, Диалог и концепт в митературе. Литература и музыка, Нижний Новгород 2001; Л.В. М и л л е р, Художественный концепт как смысловая и эстетическая категория, „Мир русского слова”, Санкт-Петербург 2000, № 4, с. 39-45.

10 Д.С. Л и х а ч е в, Концептосфера русского языка, [в:] Русская словесность. От теории словесности к структуре текста. Антология, Москва 1997, с. 17. 
Первая группа, выделенная нами, - (I) ОТНОШЕНИЯ ЖЕНЩИН ДРУГ С ДРУГОМ. Она, в свою очередь, включает в себя несколько тематических подгрупп. Рассмотрим их более подробно.

Первая подгруппа - (1) ХАМСТВО, ВРАЖДЕБНОСТЬ. Эта подгруппа включает элементы, указывающие на женское соперничество, непростые отношения. Сюда мы отнесли единицы, указывающие на применение женщинами физической силы по отношению друг к другу, а также единицы, указывающие на словесные дуэли женщин. В качестве примеров приводим: другая пришла бить мне морду; ссорились до драки; устраивали драку, а также поливала матом; тётка в сберкассе орала на меня; нахамила девушка; обещала напустить на нас братву; наезжали девушки; тёток прорвало и они заскандалили, брызгая слюной. Анализируя данные примеры, можно сделать следующие выводы: при описании враждебных отношений женщин друг с другом Арбатова оперирует стилистически сниженной, жаргонной лексикой, внедряет элементы блатной речи, характерной для советского периода ${ }^{11}$.

Вторая подгруппа - (2) ОТНОШЕНИЯ СВЕКРОВЬ - НЕВЕСТКА. Данная подгруппа включает лексические единицы, указывающие на сложные отношения женщин в кругу одной семьи. Как наиболее частотный пример мы рассматриваем союз „свекровь - невестка”. Эксцерпированные примеры: Изо всех сил враждовала с невесткой; осуждала половую разнузданность невестки; всякая женщина знает приколы своей свекрови. Арбатова описывает сильно выраженный конфликт, причиной которого может послужить непростая экономическая ситуация советской семьи, совместное проживание представительниц разных поколений, в частности жизнь в коммуналках.

Следующая выделенная подгруппа - (3) ССОРЫ ИЗ-ЗА МУЖЧИН. Здесь собраны все примеры, описывающие непростые отношения женщин, не поделивших мужчину: Матушка участвовала $b$ роковой разборке с первой женой; отбила Риткиного мужа и родила от него ребёнка; полезла в наши отношения по локоть; бабы дрались из-за него. Наличие значительного количества лексики на данную тему может быть связано с непростой демографической ситуацией в СССР в послевоенные годы, где доля женского населения заметно преобладала над долей мужского населения, представители которой, несмотря на активную борьбу властей Советского Союза, практиковали пьянство. С другой стороны, ссоры за мужчину могли быть следствием социального давления, оказываемого на женщин в СССР, ведь одинокая женщина без мужа и детей считалась несостоявшейся.

(4) НЕЙТРАЛЬНЫЕ ОТНОШЕНИЯ - так мы назвали подгруппу, которая включает примеры, описывающие повседневные, долгосроч-

11 А. Ф е с е н к о, Т. Ф е с е н к о, Русский язык при советах, Нью-Йорк 1955. 
ные отношения между женщинами: По полгода не разговаривали, желали друг другу собачьей смерти, а потом оттаивали; до обид спорили о воспитании и лечении детей, потом мирились и заряжались терпимостью. Жизнь советских семей в одной большой коммунальной квартире, отсутствие личного пространства, постоянный соседский контроль, жизнь „на виду" порождала ссоры на бытовом уровне. После очередных склок люди смирялись, заключая в итоге весьма неустойчивый, заведомо временный мир. Для советских соседских отношений характерен цикличный характер: ненависть и сплетни сменялись дружбой и тесным общением.

Последней подгруппой является подгруппа под названием (5) XOРОШИЕ ОТНОШЕНИЯ, включающая примеры, описывающие дружеские, приятельские женские отношения: имокнула меня $\mathbf{b}$ щёку; пила чай с медсёстрами, успокаивала мои психозы; Шили трикотажные кофточки из детских ползунков, вязали, кроили, потрошили комиссионки, ходили впятером по очереди $b$ одной модной шмотке; Тут пришла Наина Ельиина, села в первыи ряд с женой Черномырдина, и они стали разговаривать нормальными голосами и заливисто хохотать; Она сдруживалась с его девииами. Совместное чаепитие носило ритуальный характер во времена СССР; на кухне, в тесном кругу, женщины могли обсудить житейские проблемы, посплетничать. Совместный пошив одежды также характерен для советского и раннего постсоветского времени, когда из-за дефицита и отсутствия товаров женщинам приходилось шить самостоятельно. Следующий интересный момент - это разрушение мифа о серьезной жене высокопоставленного лица, которая, оказывается, больше не недосягаемый товарищ, а женщина с приземленными проблемами и переживаниями.

Второй обширной группой в нашей классификации является группа (II) ОТНОШЕНИЯ МУЖЧИНА-ЖЕНЩИНА. ОНа такЖе состоИт из нескольких подгрупп.

Первая из них - (1) ПРИМЕНЕНИЕ ФИЗИЧЕСКОЙ СИЛЫ ЖЕНЩИНАМИ - включает следующие примеры: однажды раскровавила ему физиономию; Верка мочила его по всей программе, трясла его за шиворот. Арбатова употребляет грубые формы, тем самым подчеркивает четко выраженную тенденцию к огрублению женской натуры во времена СССР, приобретение солдатских повадок и тюремных приемов.

Следующая подгруппа - это (2) ОХОТА ЗА МУЖЧИНОЙ, включающая две мини-подгруппы ФЛИРТ и БОЙ ЗА МУЖЧИНУ.

Мини-подгруппа ФЛИРТ включает следующие примеры: Строила глазки простуженным бугаям, к Олегу неоднократно клеились дамы с текстом, положила на него глаз; Ритка сделала на него немедленную стойку; Начала писать вокруг него восьмёрки; Весь рабочий день бегала за баянистом. Анализируя данные примеры, можно прийти к следующему выводу: цель 
советской женщины - добиться мужского внимания любыми способами. Женщина активна и находится в постоянном поиске мужчины, она больше не робеет, не ждет, а берет инициативу в свои руки. В данном случае имеем дело с отрицанием женской стереотипной пассивности. Для того чтобы подчеркнуть комичность и нелепость, Арбатова использует обороты и словосочетания, которые можно отнести к просторечию.

Вторая мини-подгруппа - БОЙ ЗА МУЖЧИНУ - включает между прочим такие примеры: отхватила подполковника, относилась к поколению, в котором дрались за мужиков; молодая женщина бульдогом виепилась b пожилого светского бабника, ценой невероятных унижений женила его на себе; Ритка подиепила голиандиа; Она в неравном бою оторвала потрясающего мужика. Приведенные примеры доказывают, что соперничество женщин друг с другом за мужское внимание было распространенным явлением. Мужчина сравнивается Арбатовой с дефицитным товаром, вещью, которую можно подиепить, оторвать $b$ бою, в которую можно вцепиться. Женщина в данном случае выступает в роли хищницы.

Третья макрогруппа представляет собой ряд наиболее частотных женских типажей, которые нам удалось выделить в ходе анализа эксцерпированной лексики. Мы назвали ее (III) ОПИСАНИЕ, ТИПАЖИ. Эта макорогруппа включает семь групп.

К первой группе, названной нами (1) ОТЛИЧНИЦА, относятся следующие примеры: асексуальная отличница $b$ пиджаке со строгой причёской; В классе сложился „отличницкий бомонд”, такие девочки с косами, тихие, аккуратные и воображалистые; Девочки с косичками, пишущие круглым почерком стихи в тетрадку; Она образцово-показательная девочка: вредная отличница с косой, из тех, кто занимается в балете, музыкальной и художественной школах, обслуживая родительские амбииии. Вырисовывается стереотипный образ умной девочки с неотъемлемым элементом - косой.

Данный образ-типаж косвенно связан с другим образом, который мы назвали (2) СТАРАЯ ДЕВА. Его иллюстрируют такие примеры, как: Злющая неустроенная баба; сексуально не обслуженные климактерические тётки; Ляля строила из себя викторианку, боялась мужчин, боялась собственной сексуальности; Хозяйкой его была старая дева, которую звали, скажем, Нона Оликова; Поэтесса была бездетна, безмужня и обручена с литературой. Данный образ - очередное стереотипное представление о женщине, не состоявшей в браке. Стилистически сниженная лексика указывает на весьма негативное отношение к такой женщине в советском обществе.

Третья подгруппа - (3) НЕОБРАЗОВАННАЯ, ПРОСТУШКА, ЛИМИТЧИЦА. Примеры: Девушка вышла из ступора и залопотала с сильным украинским говором; Разговаривала на тарабарщине; Съехавшиеся из ре- 
гионов тётеньки не понимали, кто тут кому Вася; Закройся, колхозница, выучись говорить грамотно; Не снятые у вокзала лимитчицы; Мог бы найти что-нибудь получше некрасивой провинциальной дуры. Данные примеры доказывают существование негативного отношения в советском и постсоветском обществе к девушкам из провинции, наличие стереотипа об их глупости, второсортности, косноязычии. Складывается впечатление, что наличие говора - одного из отличительных признаков иногородности - вызывало в обществе презрение и смех.

Очередной типаж - (4) БЕЗ СТИЛЯ / ВКУСА. Он может быть проиллюстрирован следующими примерами: Густо накрашенные воспитательницы; Туберкулёзного вида лиса, крашенная под красное дерево; Это была металическая тётка с мелкой завивкой, носатым пустым мицом, нелепая и грозная $b$ синем костюме; $C$ ним была злобная страхолюдина, представленная женой; Заголосила толстая тётка $b$ кримплене, золоте; Нас встретили злобные крашеные тётки и объяснили; Толстой пожилой тётки с пучком душераздирающе крашеной рыжины; накрашенные злобные бабы. Арбатова обращает внимание на такие детали, как безвкусное окрашивание волос, безвкусный макияж, полнота, злобность, использует существительные баба, тётка с целью подчеркнуть личную неприязнь к конкретной женщине.

Следующий типаж - это (5) КРАСОТКА. Он объединяет такие примеры: Красивая была девочка; Считалась главной красавицей среди сестёр; Верка была хороша как куст роз; Вышла красивая девушка и начала застенчиво улыбаться. Стоит отметить, что красота идет в паре в другими положительными качествами: обаянием, застенчивостью, миниатюрностью. Подчеркивая женскую красоту, Арбатова использует существительные женщина, дама, девушка вместо существительных баба, тётка, кукла, девка.

Шестая типажная группа - это (6) ПЬЯНИЦА-НЕУДАЧНИЦА. Она включает следующие примеры: Ютилась неопятная пьянчужка Фроська; Первая была поэтессой, из тех, кто хорош в молодости, но потом никем не становится; Красавииа поправилась, померкла, живёт в одиночестве; Дама жила в совершенно плюшкинской квартире; Жанна была филфаковка второго сорта, из тех, что преподают детям не потому, что ююбят их или умеют с ними общаться, а потому, что не состоялись как учёные. Алкоголизм, неуверенность в себе, непрофессионализм приравнивается к жизненным неудачам. Для описания женщин-неудачниц используются фамильярно-пренебрежительные суффиксы.

Последний типаж - (7) ВЛАСТНАЯ. Это типаж женщины, которая принимает решения, стоит во главе семьи; она диктатор, бой-баба, которая должна отстоять очередь, достать продукты; она ответственна за обеспечение семьи, она стойкая, предприимчивая. Приведем рад примеров: У нас всё решает мама; бабушка Ханна стопроцентно принима- 
яа решения за мужа; Она жёстко держала всю семью, была очень консервативна и даже запрещзала в доме радио вплоть до войны; Моя матушка пошиа бульдозером; Руководящая и направляющая бабушка; Мать бестолковая хозяйка, но у неё есть фамильная европейская выучка, она знает, „как надо”.

Четвертая макрогруппа - это (IV) ДЕТИ, ХОЗяЙСТВО. К группе (1) ДЕТИ имеют отношение следуюшие примеры: Мать, волокущая за руку рыдающего ребёнка; Мама пасла детей; Уже почти ненавидели собственных детеи и всё время дёргали их, орали, запрещали землю, лужи, возню и лазанье по деревьям; Они также трясутся над детьми и совершенно не понимают их; Многие матери становятся $b$ подобных ситуациях сыщиками и полицейскими, в результате чего ломают отношения на Всю оставшуюся жизнъ. Анализируя лексику, приходим к выводу, что в советском обществе наступает некое отрицание сакрализации материнства, которое в свою очередь становится долгом, повинностью. Такая тенденция может быть связана с отсутствием в СССР религии как таковой, ослаблением культа Божьей Матери.

Группа (2) ХОЗЯЙСТВО включает следующий языковой материал: Вытянули на своём горбу бабы; Садилась на диван, не разувшись, и говорила: „Я устала как Бобик!"; Приходила Вечером с полными сумками; мысль, что у женщины может быть какое-то собственное пространство, кроме кухни и работы, выглядела совершенно кошунственной. Итак, получается, что кухня и работа - единственное пространство женщины.

Последняя макрогруппа - это (V) РАБОТА. Прежде всего хочется обратить внимание на то, что Арбатова тяготеет к образованию женских форм от форм мужских профессий, широко используя следующие существительные: экскурсоводша, генеральша, тренерша, повариха, парикмахерша, библиотекарша, руссичка, математичка, биологичка, кондукторша, буфетччиа, секретарша, врачиха, логопедша, географичка, директриса. Замечательно то, что данные названия, хоть и относятся к числу стилистически сниженной лексики, не обязательно используются в негативном контексте.

Все обнаруженные нами фрагменты, связанные с женским трудом, мы условно разделили на две группы. Первой группой является группа (1) РАБОТАЮЩАЯ. К ней относятся такие примеры, как была матерью двух детей и успевала ещё работать в двух местах, все женщины вокруг работали.

Вторая группа - (2) НЕ АКТИВНАЯ - объединяет фрагменты: Ляля была писательская дочка и никогда не проявляла соииальной активности; Молодая, ничего не умеет, на работу не ходит; Работать Даша не могла и не хотела, ссылаясь на слабое здоровье; На работу она тоже не рвалась, ощущая себя обеспеченной женой; Скучающая обеспеченная женушка. Сделаем вывод: если женщина, описанная как работающая, представ- 
лена нейтрально, то женщина малоактивная предстает перед нами в негативном контексте. Женщина, выбравшая прежде привычные для нее традиционные женские обязанности (уход за домом и детьми), испытывала пресс общественного осуждения, ее клеймили „тунеядкой”, „лентяйкой" и „барыней"12. В советские времена считалось, что женщина должна трудиться наравне с мужчиной.

Итак, проанализировав образ постсоветской женщины в произведении Арбатовой, мы пришли к неоднозначным выводам. Содержание концепта имеет неоднородный и противоречивый характер. Нам удалось выяснить, что в ходе описания героинь в автобиографическом романе Мария Арбатова создала собирательный образ советской женщины, живущей в тяжелые времена на закате советской эпохи и рассвете новой постсоветской действительности. Такое непростое время требует от человека огромной внутренней силы духа, смирения, умения приспособляться к новой окружающей среде. Подобные испытания выпали на долю многих советских женщин, чьи взгляды и жизненные позиции уже сформировались в уходящую эпоху с ее особенностями, идеологией, принщипами и распорядком. Женщина очутилась в сложном положении: все, что десятилетиями вкладывалось ей советским строем, она вынуждена переоценить и суметь устоять на совершенно новой подвижной и неустойчивой почве, которая и есть настоящее.

Неоднородность содержания концепта ОНА-ЖЕНЩИНА заключается в том, что он содержит в себе многоплановый, многомерный, полифонический образ женщины переходного поколения. Женщины, воспитанные во времена СССР, изначально наделены набором определенных установок, качеств, поведений, ценностей, характерных тому времени. В процессе приспособления к новой действительности каждая представительница вынуждена комплектовать из этого множества свое новое зрелое Я. Анализ языкового материала позволил выстроить многоликий, усредненный образ. В постсоветской женщине сочетаются отзвуки бесполого „homo soveticus”, активистки, испытывающей интерес к общественной деятельности, гражданки-труженицы-матери 13 , носительницы трех социальных ролей, исполняющей свой долг перед государством и в то же время малоактивной в социальном плане тунеядки, обузы общества; сочетаются качества завистливой, скандальной, враждебно настроенной соперницы, вечно недовольной, встревающей в жизнь близких родственницы и подруги-соратницы, устраивающей чаепития; бойкой охотницы за мужским вниманием и кошельком,

\footnotetext{
12 Л.Н. 3 а в а д с к а я, Гендерная экспертиза российского законодательства, Москва 2001.

13 Там же.
} 
а также подчиняющейся и зависящей от мужского присутствия, опасающейся одиночества, клейма старой девы, с которой не считается общество. Это и сочетание признаков столичной образованной молодой девушки с необходимым набором внутренних и внешних качеств и, как противовес, необразованной, простой, косноязычной лимитчицы, безвкусно накрашенной, старой, излишне полной, или, наоборот, сухой, злобной тетки; властной, принципиальной и строгой по отношению к окружающим и измученной бытом матери, хозяйки, чей труд не ценят близкие. Этот стереотипный список макро- и микротематических мотивов можно в будущем продолжить, а также выяснить, напоминает ли портрет женщины в творчестве российской писательницы портреты героинь той же эпохи в польской литературе.

Именно поэтому в своих последующих исследованиях мы намерены изучить и представить сравнение концепта ЖЕНЩИНА в творчестве Марии Арбатовой и польской писательницы Катажины Грохоли.

\section{Библиография}

A n u s i e w i c z J., Kulturowa teoria jezyka. Zarys problematyki, Wrocław 1994.

А с к о л ь д о в С.А., Концепт и слово, см.: Е.В. Д $з$ ю б а, Концепт „ум" в русской иингвокультуре, Екатеринбург 2011.

Г а ч е в Г.Д., Жизнь художественного сознания, Москва 1972.

З а в а д с к а я Л.Н., Гендерная экспертиза российского законодательства, Москва 2001.

З у с м а н В.Г., Диалог и концепт в литературе. Литература и музыка, Нижний Новгород 2001.

Л и х а ч е в Д.С., Концеептосфера русского языка, [в:] Е.В. Д з ю б а, Концеет „ум” в русской лингвокультуре, Екатеринбург 2011.

Л и х а ч е в Д.С., Концептосфера русского языка, [в:] Русская словесность. От теории словесности к структуре текста. Антология, Москва 1997.

М и л л е р Л.В., Художественный концепт как смысловая и эстетическая категория, „Мир русского слова”, Санкт-Петербург 2000, № 4, с. 39-45.

П о п о в а З.Д., С т е р н и н И.А., Когнитивная лингвистика, Москва 2010.

С а п о ж н и к о в а Ю.Л., Жанр автобиографии: понятие и особенности, „Ученые записки Забайкальского государственного университета. Сер.: Филология, история, востоковедение" 2012, № 2, с. 56.

С т е п а н о в Ю.С., Константы: словарь русской культуры, Москва 2004.

Ф е с е н к о А., Ф е с е н к о Т., Русский язык при советах, Нью-Йорк 1955. 
